\title{
Risk in Homeopathy: Classification of Adverse Events and Homeopathic Aggravations - A Cross Sectional Study among Norwegian Homeopath Patients
}

Short Title: Risk in Homeopathy

TS: Trine Stub ${ }^{1}$, AK: Agnete E. Kristoffersen ${ }^{1}$, TA: Terje Alræk ${ }^{1}$, FM: Frauke Musial ${ }^{1}$ AS: Aslak Steinsbekk ${ }^{2}$

${ }^{1}$ The National Research Center in Complementary and Alternative Medicine (NAFKAM)

Department of Community Medicine, Faculty of Health Science, UiT The Arctic University of Norway, 9037 Tromsø, Norway

${ }^{2}$ Norwegian University of Science and Technology, Department of Public Health and General

Practice, Trondheim, Norway

Corresponding author: Trine Stub, Sykehusveien 23, UiT The Arctic University of Norway, 9037 Tromsø, Norway.

Phone: 004777649286 (work) 004792267502 (mobile)

Email: trine.stub@uit.no

Keywords: Adverse events; homeopathic aggravations; healing crisis; risk assessment; safety; homeopathy; Cross sectional survey

Highlights:

- This is the first study to apply criteria that distinguish homeopathic aggravations from adverse events when assessing patient reported worsening of symptoms during homeopathic treatment

- The patients reported worsening of symptoms 14 days after taking homeopathic remedy was classified as mild or moderate suggesting that the risk connected to homeopathic treatment is minor.

- We recommend that similar studies are undertaken to test the validity of the criteria used in this study as further development and improvement are warranted 


\section{Summary}

The registration of adverse events is important to identify treatment that might impose risk to patients. Homeopathic aggravation, a concept unique for homeopathy may impose a particular risk, as it is tolerant towards a worsening of the patients' symptoms. The aim of this study was to explore the classification of patient reported reactions as homeopathic aggravations or adverse events.

\section{Design and setting}

In a cross sectional survey, patients were asked to register any reactions they had experienced 14 days after taking homeopathic remedies. Worsening of symptoms was classified as homeopathic aggravation if it was i) an increase of the patients' existing symptoms ii) and/or a feeling of wellbeing that emerged 1-3 days after taking the remedy iii) and/or headache and/or fatigue accompanying these symptoms.

\section{Results}

A total of $26 \%$ of the participants reported worsening of symptoms. One third was classified as adverse events. Half of these were graded as minor and the other half as moderate according to the Common Terminology Criteria for Adverse Events. Two thirds were classified as homeopathic aggravations. Of these, $73 \%$ were classified as minor and $27 \%$ as moderate, giving a tendency towards milder severity for those classified as homeopathic aggravations $(p=0.065)$.

\section{Conclusion}

Patients reported a substantial part of the short-term reactions after taking homeopathic remedy as a worsening of symptoms. These reactions were classified as mild and moderate. Hence, the risk connected to homeopathic treatment is minor. More studies are needed to confirm the existence of homeopathic aggravation and how to classify the concept in a clinically meaningful way. 


\section{Introduction}

Patient safety is central for all health care practices, both within conventional medicine as well as Complementary and Alternative Medicine (CAM). Patient safety can be understood as the reduction of the risk of unnecessary harm associated with health care interventions to an acceptable minimum (1). Risk is generally defined as a compound measure of the probability of an event and the magnitude of the potentially negative outcome of that event (2). Moreover, risk can be defined as direct and indirect risk (3). Direct risk is caused by the treatment itself and linked directly to the intervention. This includes traditional adverse effects of an intervention, such as bleeding after acupuncture needling or an allergic reaction after the use of a herb, as well as risk connected to self-management advice from the practitioner (4). Indirect risk is related to adverse effect of the treatment context, e.g. the CAM practitioner, rather than the intervention. A patient may be harmed by a care context, which prevents the patient from receiving the best possible treatment relevant to her or his health needs, e.g. when patients seek a CAM practitioner for their health complaints which may be effectively treated by conventional medicine (e.g. cancer), and the CAM practitioner, often unwittingly, causes a delay of conventional treatment (4). Another example is continued care in conventional or CAM settings of unproven effectiveness and/or not in line with the patient's values or preferences whilst delaying more appropriate CAM or conventional care with positive evidence on effectiveness.

The 12 month prevalence of those who visit homeopaths in Central Europe has been found to vary between $2 \%$ in Great Britain $(5,6)$ to $15 \%$ in Germany (7). In the Scandinavian countries the prevalence of visits varies between $1.3 \%$ and $14 \%(8,9)$. According to a Norwegian survey from 2014, the prevalence of the use of homeopathy was $1.7 \%$ in 2014 (10), a decline from $4.3 \% 10$ years earlier. Hence, it is relevant to gather information about potential risks related to homeopathic care, in general, and the use of homeopathic remedies, in particular.

Homeopathic remedies are typically administered at very high dilutions also beyond Avogadro's constant $\left(6.023 \times 10^{23}\right)$ which is the threshold where no molecule of the original substance is left in the remedy. Since these remedies most often contain no or very small quantities of pharmacologically active molecules they are thought to represent no major safety concern in terms

of direct risk (11-13). It has been suggested that risk in homeopathy is related to practice more than to the homeopathic remedy (14). 
A systematic review published in 2012 of case studies of adverse effects related to homeopathic practice (15) found 30 cases that reported adverse effects of homeopathic remedies (direct risk). Another eight were related to adverse effects caused by the substitution of conventional medicine with homeopathy (indirect risk).

Homeopathic aggravation is a concept unique for homeopathy. The concept is understood as a temporary worsening of existing symptoms following the administration of a correctly chosen homeopathic remedy, which should be followed by an improvement $(16,17)$. It has many similarities with the concept of healing crisis that is common in other CAM therapies (18). A healing crisis is understood as a temporary exacerbation of symptoms on the way to more definite improvement (19).

The influential Greek homeopath George Vithoulkas defined homeopathic aggravation in a case as the optimal reaction that can be expected from a correct constitutional remedy (20). The founder of modern homeopathy Samuel Hahnemann makes several comments on the subject. In paragraph 157 in the "Organon" ( $6^{\text {th }}$ edition) he wrote: "However certain it is that a homoeopathically chosen remedy, because of its appropriateness and the minuteness of the dose, gently removes and destroys its analogous acute disease without manifesting its remaining un-homoeopathically symptoms, i.e. without arousing any new significant complaints. It is nevertheless usual (but only when the dose is not appropriately attenuated) for it to effect some small aggravation in the first hour or first few hours after the remedy is taken and for several hours if the dose is rather too large”. It appears that Hahnemann's understanding of this phenomenon was developing as he achieved more experience with potencies in medicine. In the $5^{\text {th }}$ edition in the "Organon" he wrote that the smaller the homeopathic dose the weaker and shorter lived the homeopathic aggravation. However, in the $6^{\text {th }}$ edition he wrote that the higher the dilution of the medicine, the stronger the aggravation tend to be. This latter statement confirms more closely his thesis that a high potency increases the effect of a remedy (21).

Substantial differences regarding homeopathic aggravation in clinical practice are reported. Some authors estimate that $75 \%$ of chronic cases show at one time or another an appreciable aggravation of their symptoms (21, 22). Other authors estimated a frequency of 10-20\% in clinical practice (23). These differences are likely to be at least partly due to the use of different, often not transparent, criteria for homeopathic aggravations. 
In two qualitative studies $(24,25)$ medical and non-medical homeopaths were asked about their perceptions of the difference between homeopathic aggravations and adverse effects, based on their clinical experience. Findings from these studies suggest that the most important criteria for homeopathic aggravations were i) an increase of existing symptoms, ii) and/or a feeling of wellbeing that emerges 1-3 days after taking the remedy iii) and/or headache and/or fatigue accompanying these symptoms. This process was reported by the homeopaths to continue for 4 to 8 weeks depending on the patient's general health condition and the direction of the change of the symptoms. If the aggravation continued for more than 14 days without a feeling of well-being, it was an adverse effect. The concept of homeopathic aggravation may impose a particular type of risk, as a homeopathic aggravation is tolerant towards a deterioration of the health status as part of an assumed healing process. This makes it important to know more about the frequency and seriousness of homeopathic aggravations. However, there is lack of knowledge, consistency and international agreement on how to best distinguish homeopathic aggravations from adverse events, and to determine the prevalence thereof.

The aims of the study were therefore:

1) To describe reactions reported by the patients, two weeks after taking homeopathic remedies and to classify these into no reactions, improvement of symptoms and worsening of symptoms. 2) To grade the severity of the worsening of symptoms according to the Common Terminology Criteria for Adverse Events (CTCAE). 3) To classify the worsening of symptoms into homeopathic aggravations or adverse events.

\section{Material and methods}

This study was a questionnaire based cross sectional survey. Data were collected between June, 2011 and August, 2012. The study was approved by the Regional Committee for Medical and Health Research Ethics in Northern Norway (2010/3379).

\section{Operationalization of concepts}

The worsening of symptoms, reported by the participants, were classified as adverse events [(AE(all)] before being divided into selected adverse events (AE) and homeopathic aggravations (HA). When HA was deducted from the worsening of symptoms, AE described the deteriorations 
that were classified as adverse events in the study. Homeopathic aggravation was identified according to the criteria by Stub et al., listed in the introduction $(24,25)$ (figure 1).

\section{Figure 1.}

The symptoms of the participants were classified according to the Common Terminology Criteria for Adverse Events (CTCAE) (26). In this study, adverse events were understood as all diseases, or unwanted and/or harmful reactions that appeared during the study period, regardless of their relation to the actual treatment (27). Thus, adverse event is a recommended term to describe harmful events occurring during a trial (28). Moreover, the CTCAE system grades adverse events from 1 to 5 , where 1 is mild, 2 is moderate, 3 is severe or medically significant, 4 is life threatening, and 5 is lethal.

\section{Setting}

In Norway inhabitants receive conventional medical treatment within the public health care system, while CAM-practitioners, including homeopaths, operate outside this system. Thus, patients themselves generally cover the costs of visiting a homeopath. However, most non-medical homeopaths are members of the Norwegian Homeopathic Association (NHL) that requires a professional standard regarding medical and homeopathic skills and knowledge of their members. (The threshold levels for homeopathic dilutions in Norway are D6.)

\section{Participants}

Patients who visited a homeopath for the first time, and returning patients who had new complaints or diseases that had not previously been treated by a homeopath, were eligible for the study. Patients (or their guardians) who did not understand the meaning or consequences of participating, and patients who were unable to fill in the forms were excluded from the study. Patients younger than 18 years had to obtain permission from their guardians.

\section{Recruitment}

The patients were recruited through private clinics run by NHL members. NHL contacted all practicing members by e-mail requesting them to recruit patients. Since only three homeopaths responded to this e-mail, a total of 130 of the NHL members were contacted by phone, and they all agreed to recruit patients. 
Each of the 133 homeopaths received a package of the study material for each patient. Each package contained a letter of invitation, a questionnaire, and a return envelope for the study participants. The homeopaths were instructed to consecutively invite all eligible patients at the beginning of the consultation.

Patients who accepted the invitation received the package containing the study material and were asked to complete the questionnaire fourteen days after taking the homeopathic remedy, and return it to the study administration along with the signed consent letter. The fact that the patients actually returned the completed questionnaire was considered a consensus in itself.

Due to low response rates, a reminder was sent to the homeopaths six months after the study started. Nineteen homeopaths withdrew from the study, while 114 agreed to continue to recruit patients. Homeopaths who wanted to recruit more than 15 patients received additional packages.

\section{Data collection}

The four-page questionnaire contained questions about demographics, reasons for encounter and reactions after treatment. The demographic information included age (those 15 years and younger were classified as children), gender, marital and work status, education, and information about the complaints or diseases (maximum three) that were the reason for visiting the homeopath. The participants' initial complaints or diagnoses were categorized according to the International Classification of Primary Care (ICPC-2) (29) (table 4).

All participants were asked to report their reactions fourteen days after taking the homeopathic medication. In the questionnaire they were asked: We are interested in knowing what kind of reactions you have experienced after having taken homeopathic medication. Please note all kinds of reactions, regardless of your own opinion about the cause. Therefore, the term "reactions" includes all changes of symptoms or appearance of new symptoms that the study participants experienced in the time after they had taken the homeopathic medication (table1).

\section{Table 1}

\section{Classification}

Figure 2 gives an overview of the classification process in this study.

\section{Figure 2}


The first author evaluated the reactions as no reactions, improvement of symptoms or worsening of symptoms. The adverse effects (worsening of symptoms) were classified independently by two medical doctors (MDs). The process was conducted in stages with the aim to reach consensus. Any disagreement was reanalysed until consensus was reached. The first author guided this process. After the CTCAE grading was completed and consensus reached, two classical homeopaths (one being the first author) evaluated which of the adverse events [AE(all)] that could be classified as homeopathic aggravation (HA). They evaluated the adverse events [AE(all)] independently. Afterwards they met to discuss and reach consensus.

\section{Statistical analysis}

Initially, data were analyzed descriptively. Then differences between gender, adults and children were analyzed using the Pearson chi-square test and the Fisher's Exact Test. Pearson chi-square using the Monte Carlo procedure, was applied to test for difference in severity grades for homeopathic aggravations and adverse effects. A significance level of $\mathrm{p}<0.05$ was applied. All data were analyzed using the SPSS statistical version 19.0 (SPSS Inc., Chicago, USA).

\section{Results}

A total of 133 homeopaths were asked to recruit patients to the study and all agreed to receive the study material. Of these, 48 returned data about patients they had invited. The majority of the homeopaths were female $(n=40)$ and all had practiced homeopathy for at least five years. All of them were located in or close to the largest towns in Norway. The homeopaths reported that 706 patients accepted to participate in the study. However, 390 patients did not respond, and 28 returned empty questionnaires. Questionnaires were returned by 288 (41\%) patients and included in the analysis (figure 3).

\section{Figure 3}

The mean age of the participants was 39 years, and $72 \%(n=207)$ were female. Twenty percent $(n=56)$ were children (15 years or younger). The majority of the participants (54\%) were married or lived with a registered partner. The adult informants were highly educated, $46 \%$ had a university degree, and the majority was currently working (62\%) (table 2).

\section{Table 2}


The 288 participants reported a total of 503 initial complaints (an average of 1.7 complaints per participant): 134 participants reported one complaint, 87 reported two complaints, and 65 reported three complaints at the initial consultation. Two participants did not answer the question.

A total of $43 \%(n=113)$ of the participants reported that the first complaints had lasted up to 1 year, $25 \%(n=65)$ up to 5 years, and 32\% $(n=84)$ reported more than 5 years' duration. A total of 51\% ( $n=140$ ) used conventional medicine for their initial complaints. The three most frequently reported complaints were psychological (23\%), respiratory (22\%) and digestive (15\%).

When all complaints were analyzed together (the first, second and third complaint reported by the participants) the distribution of the complaints were: Thirty percent reported general pain and weakness, 23\% skin conditions, such as atopic eczema, 18\% neurological conditions, and 11\% psychological conditions, such as anxiety and sleep disturbance. Each of the following complaints constituted less than 10\%: Digestive conditions, asthma and allergy, and female genitalia complaints (table 4).

\section{Table 4}

\section{Classification of reactions}

Patient reported reactions

About half $(53 \%, \mathrm{n}=154)$ of the 288 participants did not report any reaction after having taken homeopathic remedies, while 21\% $(n=60)$ reported improvements, and $26 \%(n=74)$ reported worsening of the symptoms (figure 4).

\section{Figure 4}

A total of 116 of the 134 participants reporting a reaction answered the question regarding the time span between taking the homeopathic remedy and the occurrence of the reactions. Seventy-three percent $(n=85)$ reported that the reactions appeared one to three days after taking the remedy, and $77 \%(n=82)$ reported that the reactions lasted up to one week. A total of $78 \%(n=93)$ attributed the reactions to the remedy given to them by the homeopath. There were no differences between the worsening and improvement of symptoms regarding the onset of reactions or link to the homeopathic remedy. Regarding the duration of the reactions, however, the improvement lasted longer than the worsening $(\mathrm{P}=0.003)$ (table 3). 


\section{Table 3}

\section{Classification of severity and differentiation of adverse events and homeopathic aggravations}

In their first round of classification the two MDs reached a consensus of $76 \%(n=56)$. When reevaluating the questionnaires with no complete agreements, a consensus of $99 \%(n=73)$ was obtained. After the third evaluation complete consensus was reached. Sixty-six percent $(n=49)$ of the adverse events [AE(all)] were classified as CTCAE grade 1 and $34 \%(n=25)$ as grade 2 . None were graded 3, 4 or 5 .

In the next step, two homeopaths identified the homeopathic aggravations (HAs) from the group of all adverse events [AE(all)]. In the first evaluation, the two homeopaths reached a consensus of 92\% ( $\mathrm{n}=68)$ and complete consensus was reached in a second evaluation. They reported that the challenge of classifying the HAs was to determine whether the worsening of symptoms was related to new symptoms or deterioration of existing symptoms. Such a situation is illustrated in the following example: The mother of a girl with atopic eczema wrote in the questionnaire: "She (the daughter) felt that the skin started to burn before going to bed. This started 3-4 hours after she had taken the medication and lasted for at least 2-7 hours during the five days she took the medication”. The mother wrote that the daughter had never complained about this before. One homeopath classified this as adverse event and interpreted the burning of the skin as a new symptom. The other interpreted the symptom as an exacerbation of the itching and, consequently, classified it as homeopathic aggravation. After some discussion they concluded that the burning of the skin was homeopathic aggravation due the fact that the exacerbation started shortly after taking the medication. (The MDs evaluated this reaction as CTCAE 2.)

Sixty-six percent $(n=49)$ of all adverse events [AE(all)] were classified as HA. The severity of these had previously been classified by the MDs as grade $1(73 \%(n=36))$ and grade $2(27 \%(n=13))$. The remaining (34\% ( $n=25)$ ) was classified as adverse events. Of these $52 \%(n=13)$ had been classified as grade 1 and $48 \%(n=12)$ as grade 2 . This gave a tendency towards milder severity for those classified as homeopathic aggravation $(p=0.065)$ (figure 5).

\section{Figure 5}




\section{Discussion}

The main finding from this study suggests that the risk connected to homeopathic treatment is minor. One of four patients visiting homeopaths reported worsening of symptoms which were classified as mild or moderate. The worsening of symptoms was classified as homeopathic aggravation for two out of three patients.

Clear definitions and criteria (30) to distinguish homeopathic aggravations from adverse events may enhance patient safety and improve comparability between studies in the future. The strength of this study is, thus, that it for the first time applied such criteria to distinguish homeopathic aggravations from adverse events which were based on a systematic review performed as part of a doctoral thesis (4) and information from two qualitative studies $(24,25)$. According to the homeopaths, who evaluated the data, these criteria were clear and applicable, which was reflected by the high percentage of consensus (92\%) in the first stage of the evaluation process.

This study has several limitations. First, there might be disagreement about the criteria for HA used. According to homeopathic philosophy (31-33) the aggravation of patient's symptoms depends on whether the case is acute, chronic or acute with chronic sequels. According to the literature, homeopathic aggravations may last for minutes and hours in acute conditions and days, weeks or even months for chronic conditions. The three day cutoff time to distinguish homeopathic aggravations from adverse events may, therefore, appear arbitrary. From a safety perspective, this time-based criterion may insure that patients with severe symptoms are referred in time to conventional treatment. However, the time criteria is only one criteria used to distinguish homeopathic aggravations from adverse events. In clinical practice the homeopath should apply all the criteria simultaneously when evaluating the patient deteriorations (25).

The influential Greek homeopath George Vithoulkas defined homeopathic aggravation in a case as the optimal reaction that can be expected from a correct constitutional remedy. Hence, a positive reaction and as such a part of the healing process (32). However, in this study the focus was risk connected to the concept of homeopathic aggravation. A homeopath with limited medical and/or homeopathic training, who does not know how to interpret the deteriorations that may occur during a healing process, may be risky for the patients.

Another limitation regarding the criteria for HA used in this study is the concept of well-being. Based on research from clinical practice (24), a sense of well-being may be understood as improved 
sleep and energy, improved mental and emotional capacity and feeling more balanced. If this feeling occurs soon after taking the remedy, it indicates that the curative process had started even though the original symptoms may be worse. This understanding of well-being was applied in this study.

The response rate was low (41\%), which may be a threat to the validity of the results of this study, because the non-responders may differ significantly from those who responded (34). Visitors to practitioners of homeopathy in Norway tend to be highly educated females, between 30-39 years old who have chronic complaints $(9,35)$, which are in accordance with the findings from this present study. This suggests that non-response bias probably imposes no major threat to the validity of the results. Another issue is that the sample was too small for estimating any likelihood of detecting the most severe reactions. Thus, the results from this study cannot be used to claim that there are no severe reactions from homeopathic treatment.

The prevalence of adverse events of 26\% (including homeopathic aggravations) in this study was found to be higher compared to other studies. A report based on data from observational studies and surveys (12) showed that the proportion of patients that reported adverse effects from homeopathic treatment fluctuates between $2 \%$ (36) and $11 \%$ (37). A systematic review of randomized controlled trials found that adverse effects were reported by $9 \%$ in the homeopathy groups and $6 \%$ in the placebo groups (38). However, due to the belief that homeopathy is natural and, therefore, safe and harmless it might be that adverse events are not reported by patients as they are not thought to originate from the treatment $(13,39)$.

The frequency of homeopathic aggravations in the present study was substantial with $17 \%$ of all participants classified as having experienced homeopathic aggravations. Other studies have reported that the prevalence of homeopathic aggravations vary between $10 \%(23)$ and $75 \%(21,22)$. Our findings is almost similar to those of Thompson et al. (37) who found that $22 \%$ of the study participants reported worsening of symptoms followed by an improvement after homeopathic treatment. Rossi et al. (40) reported an incidence of homeopathic aggravations of 6\%. The discrepancy in numbers may be explained by recall bias (41), as the data from Rossi et al. was recorded 4-10 weeks after the first consultations, and the data from the present study was recorded fourteen days after taking the homeopathic remedy. Moreover, the majority of the participants 
reported that clinical reactions appeared one to three days after taking the homeopathic remedy, and that the reactions lasted up to one week.

A possible explanation for the relatively high frequency of worsening of symptoms found in this study may be that the homeopaths, as a part of the homeopathic consultation, often informed patients that as part of the healing process they may experience an aggravation of their symptoms. This practice can lead to a nocebo effect (42). The rationale for interpreting these aggravations as nocebo effects is the short timeframe between the administration of the remedy and the reported reactions (reactions were reported 14 days after taking the remedy). In Norway it is common to have written information regarding homeopathic aggravation on the back of the prescription given to the patients. This practice may be an independent predictor of the occurrence of homeopathic aggravations, and could have affected the prevalence of homeopathic aggravations in this study.

Symptoms of the ongoing disease after taking a drug which is not effective follows the Natural History of the Disease (43). If a patient who is visiting a homeopath experiences worsening of the symptoms, the homeopath must evaluate the situation. If the patient sees the homeopath during a point in time, when the symptoms are just before peaking, he or she may experience an initial worsening of symptoms, followed by an improvement, as part of the natural history of the disease. However, if patients experience a sense of wellbeing, simultaneously with the deteriorations they have, according to the theory, a homeopathic aggravation because a sense of wellbeing is a hallmark of a homeopathic aggravation (44).

This study revealed that there are many unanswered questions regarding the concept of homeopathic aggravation. The main question is perhaps whether homeopathic aggravation is a meaningful concept to apply when evaluating patients deteriorations. Should homeopathic aggravation be considered an adverse event and recorded as such? However, if homeopathic aggravation is a meaningful way to evaluate patients symptoms, is it just the current symptoms that should be reported or should we report deteriorations of old symptoms as well? This present study does not have any data from the patients' disease history except for a brief description of the complaints that was the reason for visiting the homeopath. A full exploration of the patients' disease history and their report of the reactions is likely to have altered the classification of homeopathic aggravations somewhat. How to better describe or define what can be expected in response to a homeopathic treatment, must be investigated in future studies. 
Adverse events in homeopathic practice, including those that are interpreted as homeopathic aggravations, are common. This demonstrates how important it is for homeopaths and clinicians to include the concept of adverse events in their theory and clinical practice. Taking safety precautions seriously will improve the credibility of the homeopathic profession and enhance patient safety. The reactions after homeopathic treatment were reported as mild and moderate, which suggests that there is no need to take action now. However, the treatment is widely used and more safety data is needed. Consequently a surveillance program is recommended.

The criteria used in this study to classify worsening of symptoms as either homeopathic aggravations or adverse events, have not been used and verified in other studies. Further use of these criteria in research will reveal whether they are valid for homeopathic research. However, we consider these criteria as a starting point, and further development and improvement are warranted. In addition, we recommend that similar studies are undertaken, to test the validity of the criteria used in this study.

A substantial part of the short time reaction after taking homeopathic remedy was reported by patients as a worsening of symptoms. These reactions were classified as mild or moderate, suggesting that the risk connected to homeopathic treatment is minor. More studies are needed to confirm the existence of homeopathic aggravation, and, accordingly, how to classify it in a clinically meaningful way.

\section{Acknowledgements}

We want to thank Ingemar Rödin, Vinjar Fønnebø and Per Schrader for participating in the consensus processes. In addition, we want to thank Jane Ekelund and Åsa Sohlén for technical support, NHL for financial support and the homeopaths and patients for participating in this study.

\section{Competing interests}

The authors declare that they have no competing interests and no financial interest exists. This study meets the standard of the Helsinki Declaration in its revised version of 1975 and its amendments of 1983, 1989 and 1996.

\section{Authors' contribution}


TS developed the concept and design, performed the data collection, analyses and interpretation, developed the graphs, performed the literature research and drafted the manuscript. AK contributed to the data collection, analyses, processing and interpretation, revision of the manuscript. TA revised the manuscript, collected and supervised initial data. FM contributed to the data analyses and interpretation, developed the graphs, structured and revised the manuscript. AS developed the initial questionnaire and the design of the study, made recommendations and evaluations of the graphs and data analyses, and several revisions of the manuscript. All authors contributed to the final manuscript. 


\section{References}

1. Runciman W, Hibbert P, Thomson R, van der Schaaf $T$, Sherman $H$, Lewalle P. Towards an International Classification for Patient Safety: Key concepts and terms. Int Journal for Quality in Health Care. 2009;21(1):18-26.

2. Davis EM. Risky Business: Medical Discourse, Breast Cancer, and Narrative. Qualitative Health Research. 2008;18(1):65-76.

3. Ernst E. Intangible risks of complementary and alternative medicine. Journal of Clinical Oncology 2001;19(8):2365-6.

4. Stub T. Safety of Treatment Provided by Homeopaths - Homeopathic Aggravations, Adverse effects and Risk Assessment. NAFKAM skriftserie No.9 Troms $\varnothing$ : UiT The Arctic University of Norway, Troms $\varnothing 2013$.

5. Thomas $\mathrm{K}$, Coleman $\mathrm{P}$. Use of complementary and alternative medicine in a general population in Great Britain. Results from the National Omnibus Survey. J Public Health (Oxf). 2004;Jun;26(2):152-7.

6. Frass M, Strassl RP, Friehs H, Müllner M, Kundi M, Kaye AD. Use and Acceptance of Complementary and Alternative Medicine Among the General Population and medical Personnel: A Systematic review. The Ochsner Journal. 2012;12(1):45-56.

7. Haertel U, Volger E. [Use and acceptance of classical natural and alternative medicine in Germanyfindings of a representative population-based survey]. Forsch Komplementärmed Klass Naturheilkd. 2004;Dec;11(6):327-34.

8. Hansen B, Grimsgaard S, Launs $\varnothing$ L, Fønneb $\varnothing$ V, Falkenberg T, Rasmussen K. Use of comlementary and alternative medicine in the Scandinavian countries. Scandinavian Journal of Primary Health Care. 2005;23:52-62.

9. Løhre A, Rise MB, Steinsbekk A. Characteristics of visitors to practitioners of homeopathy in a large adult Norwegian population (the HUNT 3 study). Homeopathy. 2012;101(3):175-81.

10. Nasjonalt forskningssenter innen komplementær og alternativ medisin (NAFKAM). NAFKAMunders $\varnothing$ kelsen 2014, Bruk av alternativ behandling i Norge Troms $\varnothing$ : Nasjonalt informasjonssenter for alternativ behandling (NIFAB); 2014 [cited 2015 30.01.2015]. Available from: http://nifab.no/hva er alternativ behandling/tall og fakta/nafkam undersoekelsen 2014.

11. World Health Organization (WHO). Safety issues in the preparation of homeopathic medicines. Geneva: World Health Organization, 2009.

12. The European Council for Classical Homeopathy. The Safety of Homeopathy. An ECCH Report. Norfolk, United Kingdom: European Council for Classical Homeopathy, 2009.

13. Bornhöft G, Wolf U, von Ammon K, Righetti M, Maxion-Bergemann S, Baumgartner S, et al. Effectiveness, Safety and Cost-Effectiveness of Homeopathy in General Practice-Summarized Health Technology Assessment. Forschende Komplementärmedizin und klassische Naturheilkunde. 2006;13(2):19-29.

14. Fisher P, Dantas F, Rampes H. The safety of homeopathic products J R Soc Med. 2002;95(9):4746.

15. Posadzki P, Alotaibi A, Ernst E. Adverse effects of homeopathy: A systematic review of published case reports and case series. Int J Clin Pract. 2012;Des;66(12):1178-88.

16. Hahnemann S. Organon der Heilkunst. 2000.

17. Kent J. Lectures on Homeopathic Philosophy. New Dehli: B.Jain Publishers; 1900.

18. Pitchford P. Healing with Whole Foods. Asian Traditions and Modern. 3 ed. Berkely, California: North Atlantic Books; 2002.

19. Calabrese C. Clinical research in naturopathic medicine. In: George Lewith, Wayne B Jonas, Harald Walach, editors. Clinical Research in Complementary Medicine. Edinburgh: Churchill Livingstone; 2002.

20. Vithoulkas G. True but strange? Nature. 1996;383(6599):383.

21. Popova T. Homeopathic aggravations. Br Hom J. 1991;80:228-9. 
22. Paterakis S, Bachas I, Vithoulkas G. Statistical data on aggravation after the similimum. Hahnemann Homeopathic Sand. 1990;14(8):155-9.

23. Grabia S, Ernst E. Homeopathic aggravations: A systematic review of randomised, placebocontrolled clinical trials. Homeopathy. 2003;92:92-8.

24. Stub T, Salamonsen A, Alræk T. Is it Possible to Distinguish Homeopathic Aggravation from Adverse Effects? A Qualitative Study. Forsch Komplementärmed und Klass Naturheilkd. 2011;19(1):13-9.

25. Stub T, Alraek T, Salamonsen A. The Red flag! risk assessment among medical homeopaths in Norway: A qualitative study. BMC Complement Altern Med. 2012;12(1):150.

26. U.S. Department of Health and Human Services. Common Terminology Criteria for Adverse Events v4.0 (CTCAE). National Institutes of Health, National Cancer Institute 2010.

27. Statens legemiddelverk (Norwegian Medicines Agency). Bivirkningsrapporten 2011. Seksjon for legemiddelovervåkning. Oslo: Statens legemiddelverk, 2011.

28. Edwards IR, Aronson JK. Adverse drug reactions: definitions, diagnosis, and management. The Lancet. 2000;356(9237):1255-9.

29. Lamberts H, Wood M. International Classification of Primary Care. Oxford University Press. 1987.

30. Brien SB, Harrison H, Daniels J, Lewith G. Monitoring improvement in health during homeopathic intervention. Development of an assessment tool based on Hering's Law of Cure: the Hering's Law Assessment Tool (HELAT). Homeopathy. 2012;101(1):28-37.

31. Pashero TP. Homeopathy. Haas P, editor. Buenos Aires: Beaconsfield Publisher LTD; 2000.

32. Vithoulkas $G$, Woensel $E$ van. Levels of Health practical applications and cases. Athen: International Academy of Classical Homeopathy; 2010.

33. Close S. The Genious of Homeopathy - Lectures and Essays on Homeopathic Philosophy. Jain K, editor. New-Delhi: B.Jain Publishers (P) LTD; 2005.

34. Halbesleben JRB, Whitman MV. Evaluating Survey Quality in Health Services Research: A Decision Framework for Assessing Nonresponse Bias. Health Services Research. 2013;48(3):913-30.

35. Quandt S, Verhoef M, Arcury T, Lewith G, Steinsbekk A, Kristoffersen A, et al. Development of an international questionnaire to measure use of complementary and alternative medicine (I-CAM-Q). J Altern Complement Med. 2009;15(4):331 - 9.

36. Anelli M, Scheepers L, Sermeus G, van Wassenhoven M. Homeopathy and health related Quality of Life: A survey in six European countries. Homeopathy. 2002;91:18 - 21.

37. Thompson E, Barron S, Spence D. A preliminary audit investigating remedy reactions including adverse events in routine homeopathic practice. Homeopathy. 2004;93(4):203-9.

38. Dantas F, Rampes H. Do homeopathic medicines provoke adverse effects? A systematic review. $\mathrm{Br}$ Hom J. 2000;89:35-8.

39. Dantas F. Reproting and investigating adverse effects of homeopathy. Br Hom J. 1999;88:99-100.

40. Rossi E, Bartoli P, Bianchi A, Endrizzi C, Da Fré M. Homeopathic aggravation with Quinquagintamillesimal potencies. Homeopathy. 2012;101:112-20.

41. Bordens KS, Abbott BB. Research Design and Methods. A Process Approach. Fifth Edition ed. Boston: McGraw-Hill Higher Education; 2002.

42. Enck $P$, Bingel U, Schaedlowski M, Rief W. The placebo response in medicine: Minimize, maximize or personalize. Nature Review Drug Discovery. 2013;12(March):191-204.

43. Jekel JF, Katz DL, Elmore JG, Wild DMG. Epidemiology, Biostatistics, and Preventive Medicine. Third ed. Philadelphia: Saunders Elsevier; 2007.

44. Stub T, Salamonsen A, Kristoffersen A, Musial F. How to Handle Worsening of Condition during Treatment - Risk Assessment in Homeopathic Practice. Forsch Komplementmed. 2015;1; DOI $10.1159 / 00377644$. 

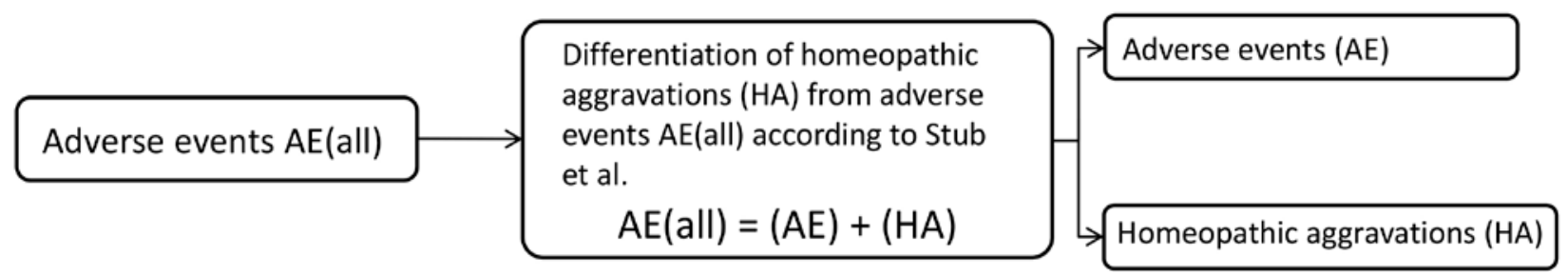

Figure 1: The relationship between the concepts of all worsening of symptoms, which was a priori defined as adverse effects [AE(all)], homeopathic aggravations (HA) and adverse events (AE). 


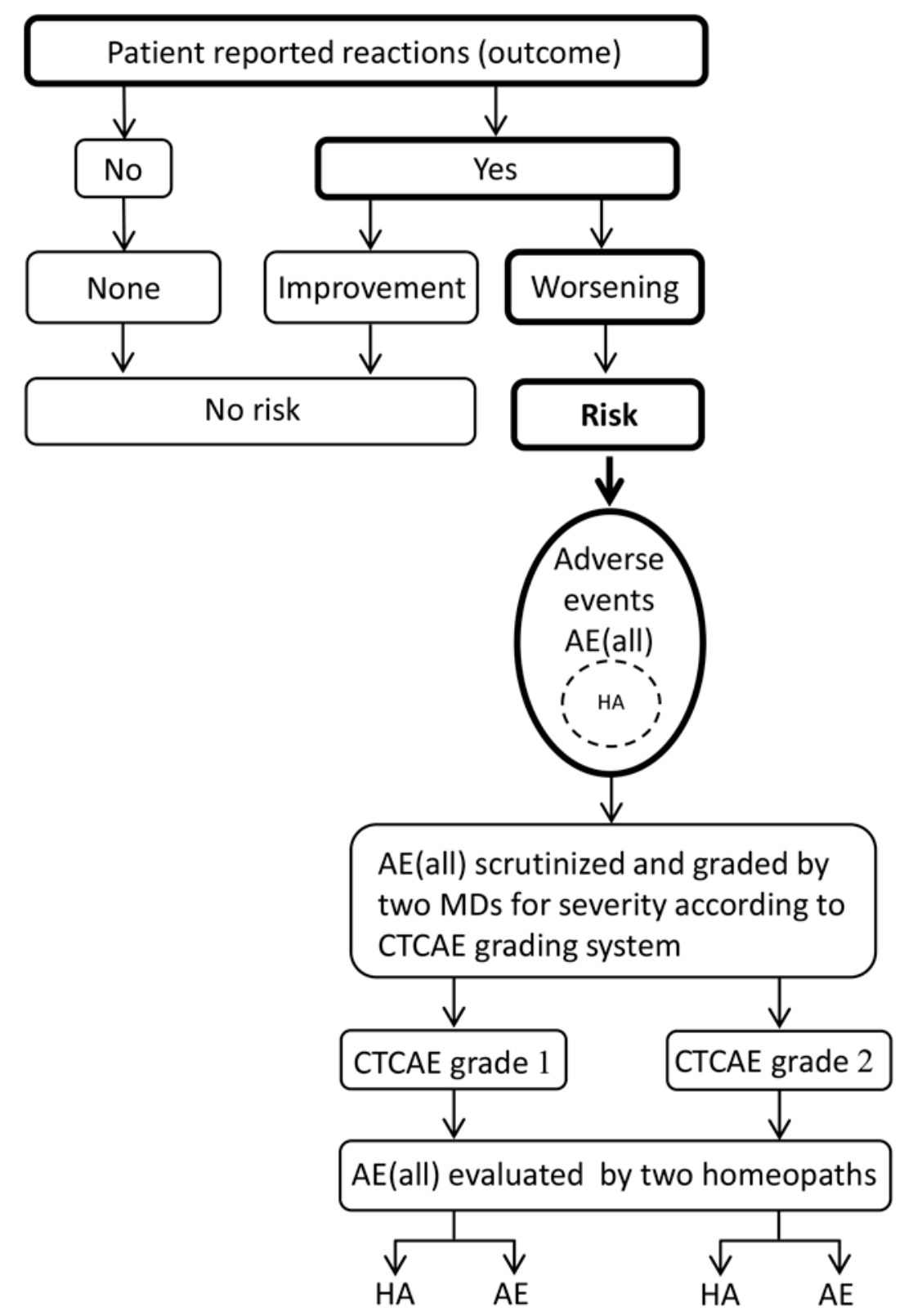

Figure 2: Classification and categorization of patient reported reactions that were attributed to homeopathic treatment. 


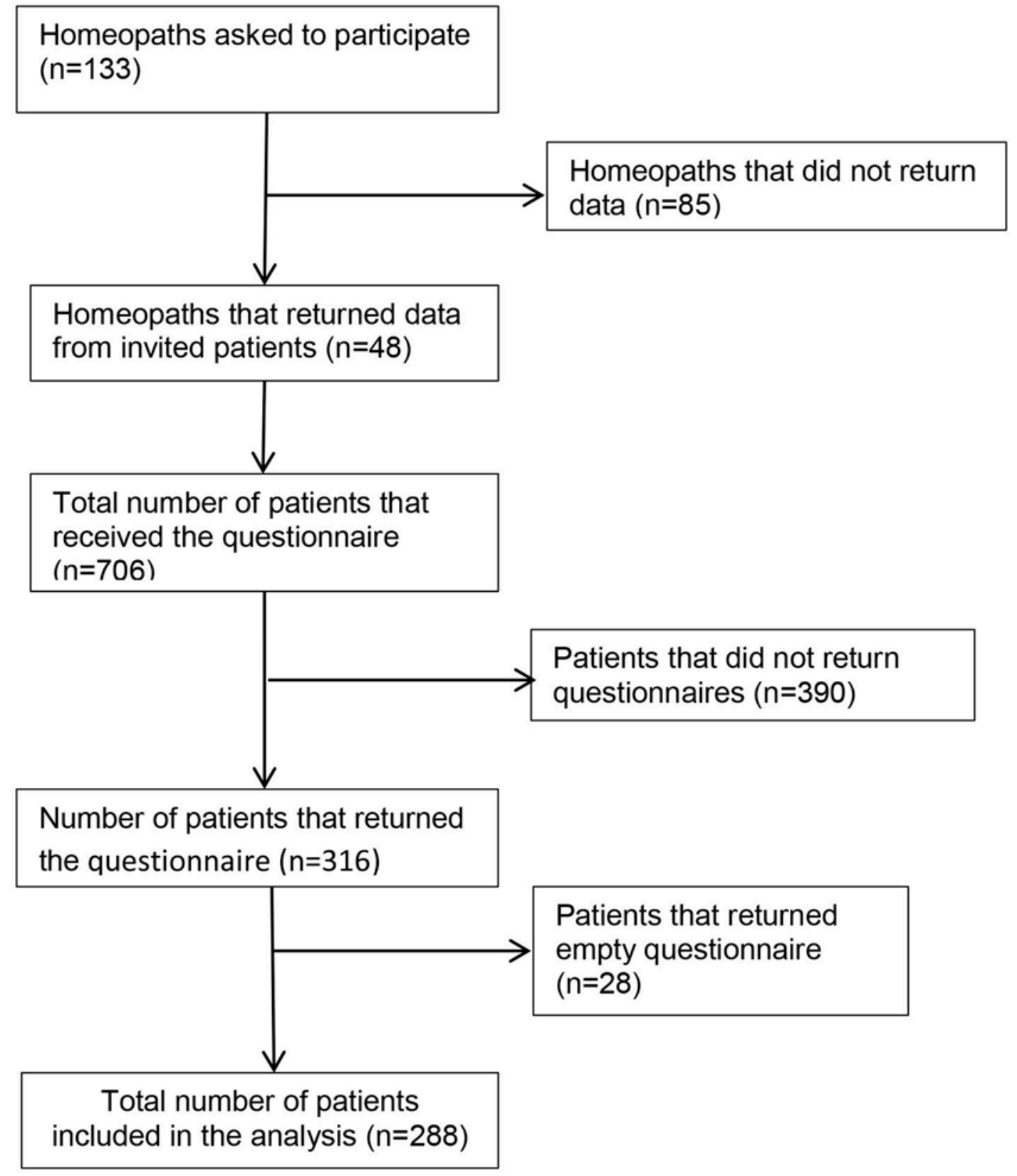

Figure 3: Flow chart of the inclusion process. 


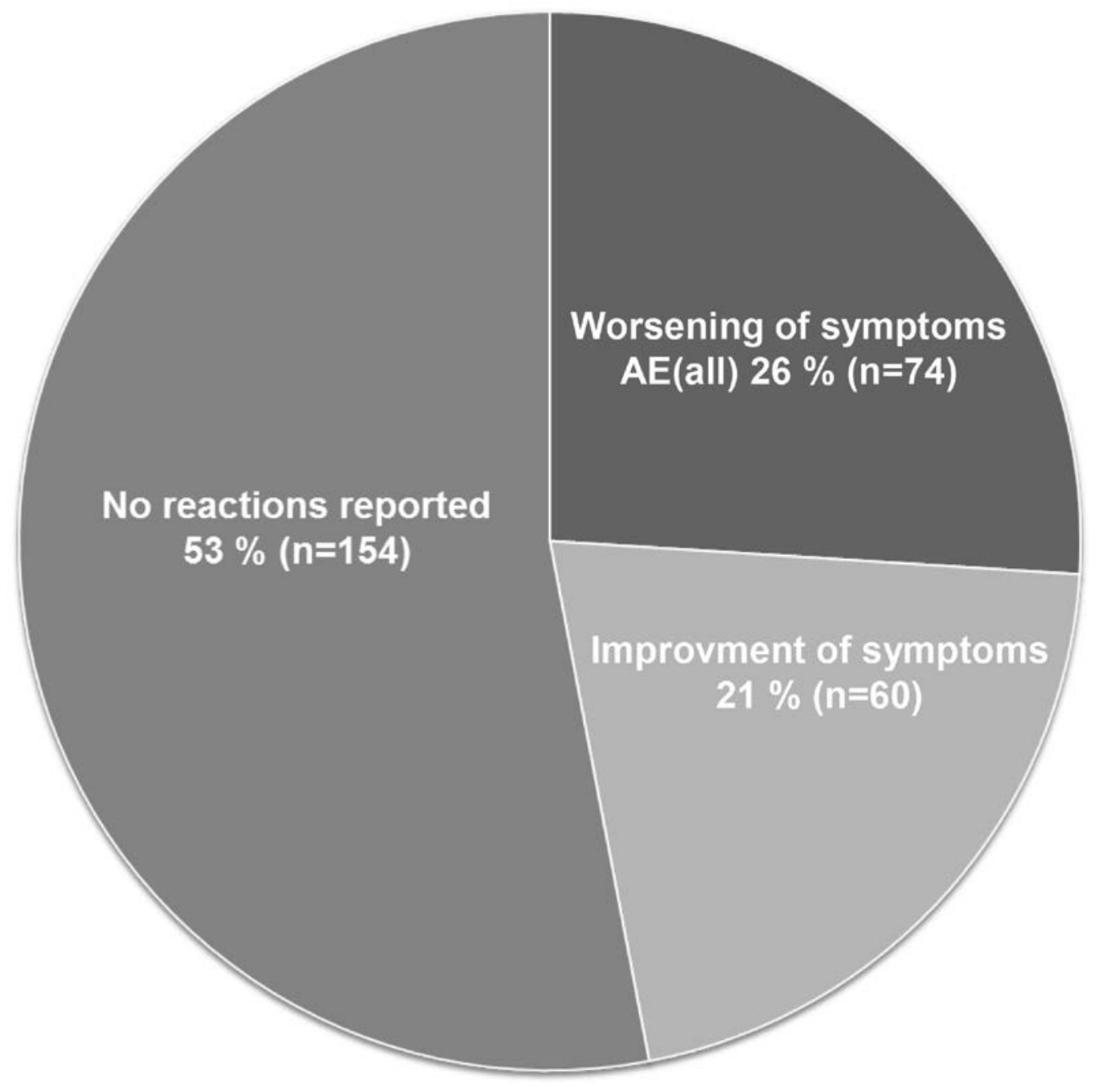

Figure 4: Distribution of the number of patient reporting reactions 14 days after taking homeopathic remedies ( $\mathrm{n}=288$ ). If a participant reported that at least one of the reactions was a worsening, the participant was categorized as worsening of symptom. 


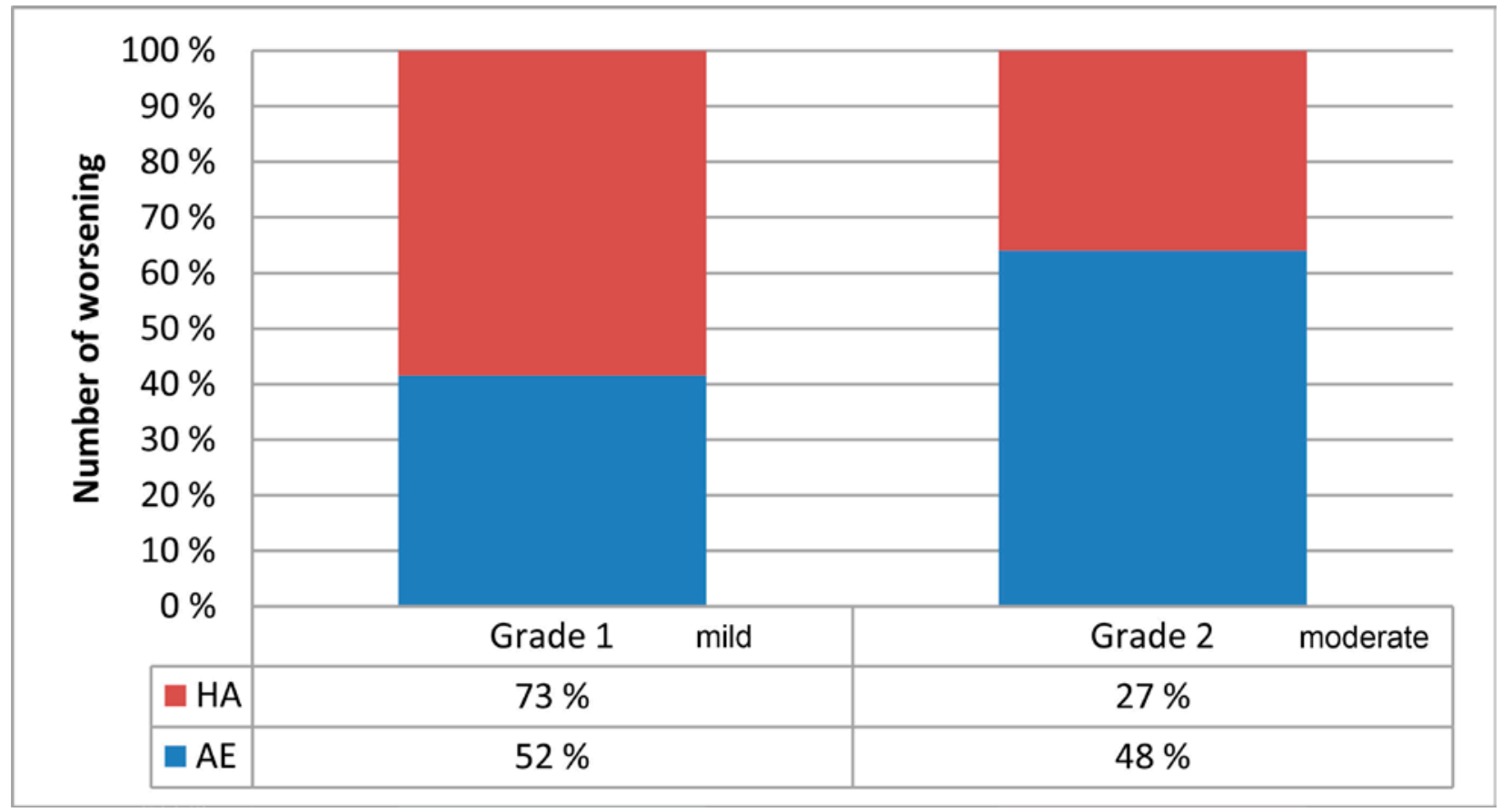

Figure 5: Worsening of symptoms, $\mathrm{AE}(\mathrm{all})(\mathrm{n}=74)$ classified according to the CTCAE grading system and differentiated as HA $(n=49)$ and AE $(n=25)$. 
Table 1: Questions regarding reactions after treatment.

\begin{tabular}{|c|c|c|}
\hline Theme & Questions & Response options \\
\hline \multirow[t]{2}{*}{ Indirect risk } & $\begin{array}{l}\text { Do you use or have you used } \\
\text { medication for your illness/disease } \\
\text { prescribed by a physician? }\end{array}$ & $\begin{array}{l}\text { Yes/No } \\
\text { If yes, provide name of the medication }\end{array}$ \\
\hline & $\begin{array}{l}\text { What kind of advice did the } \\
\text { homeopath give you regarding } \\
\text { this medication? }\end{array}$ & $\begin{array}{l}\text { No advice from the homeopath on } \\
\text { changing the medication(s)/ The } \\
\text { homeopath adviced you to discuss this } \\
\text { matter with your physician with the aim of } \\
\text { possibly reducing or changing the use of } \\
\text { medication(s)/ The homeopath adviced } \\
\text { you to reduce or change the use of } \\
\text { medication(s)/ The homeopath did not } \\
\text { discuss this matter with you. }\end{array}$ \\
\hline No reactions & $\begin{array}{l}\text { I have not experienced any } \\
\text { reactions }\end{array}$ & $\begin{array}{l}\text { Mark here } \\
\text { You have completed the questionnaire }\end{array}$ \\
\hline \multirow{4}{*}{$\begin{array}{l}\text { Describe the } \\
\text { reaction you have } \\
\text { experienced after } \\
\text { having taken } \\
\text { homeopathic } \\
\text { medication }\end{array}$} & $\begin{array}{l}\text { 1. What did you experience } / \text { hat } \\
\text { was the reaction? }\end{array}$ & $\begin{array}{l}\text { Please write here (Please add an extra } \\
\text { sheet of paper if you have experienced } \\
\text { additional reactions, or need more space.) }\end{array}$ \\
\hline & $\begin{array}{l}\text { 2. For how long did the reaction } \\
\text { last? }\end{array}$ & List the number of hours/days/weeks \\
\hline & $\begin{array}{l}\text { 3. After you had taken the } \\
\text { homeopathic medication, how } \\
\text { long did it take before you } \\
\text { experienced the reaction? }\end{array}$ & List the number of hours/days/weeks \\
\hline & $\begin{array}{l}\text { 4. Did you connect the reaction to } \\
\text { the homeopathic medication? }\end{array}$ & Yes/No /Don't know \\
\hline
\end{tabular}


Table 2: Characteristics of the participants $(\mathrm{N}=288)^{*}$

\begin{tabular}{|c|c|}
\hline Table2: Sociodemographic data & $\%(n)^{*}$ \\
\hline \multicolumn{2}{|l|}{ Gender } \\
\hline Females & $72(207)$ \\
\hline Males & $28(81)$ \\
\hline \multicolumn{2}{|l|}{ Age } \\
\hline $0-15$ & $20(56)$ \\
\hline $16-25$ & $10(28)$ \\
\hline $26-40$ & $21(60)$ \\
\hline $41-60$ & $31(88)$ \\
\hline $61-94$ & $19(54)$ \\
\hline \multicolumn{2}{|l|}{ Level of education } \\
\hline Compulsory & $16(36)$ \\
\hline Middle level & $38(86)$ \\
\hline University & $46(101)$ \\
\hline \multicolumn{2}{|l|}{ Marital status } \\
\hline Single & $19(55)$ \\
\hline Married/Registered partner & $55(156)$ \\
\hline Widow/Widower & $7(20)$ \\
\hline $\begin{array}{r}\text { Children living with one or two } \\
\text { parent(s) }\end{array}$ & $19(53)$ \\
\hline \multicolumn{2}{|l|}{ Currently working } \\
\hline Yes & $62(159)$ \\
\hline
\end{tabular}

${ }^{1}$ Due to different response rates to each question, the numbers do not always add up to the total number (288). 
Table 3: Onset of reactions, duration and link to the homeopathic remedy

\begin{tabular}{|r|c|c|c|c|}
\hline $\begin{array}{r}\text { Table 3: How long after taking the } \\
\text { remedy did the reaction appear? }\end{array}$ & $\mathbf{\%}(\mathbf{n})^{*}$ & $\begin{array}{c}\text { Improvement } \\
\mathbf{\%} \mathbf{( n )}\end{array}$ & $\begin{array}{c}\text { Worsening } \\
\mathbf{\%}(\mathbf{n})^{*}\end{array}$ & P-value \\
\hline 1-3 days & $73(85)$ & $78(28)$ & $71(57)$ & 0.413 \\
\hline 4-7 days & $21(24)$ & $14(5)$ & $24(19)$ & \\
\hline 8 days or longer & $6(7)$ & $8(3)$ & $5(4)$ & \\
\hline How long did the reaction last? & & & & \\
\hline 1day & $26(28)$ & $33(11)$ & $23(17)$ & 0.003 \\
\hline 2-7days & $51(54)$ & $30(10)$ & $59(44)$ & \\
\hline 8-14days & $15(16)$ & $15(5)$ & $15(11)$ & \\
\hline Longer than 14 days & $8(9)$ & $21(7)$ & $3(2)$ & \\
\hline $\begin{array}{r}\text { Do you link the reaction to the } \\
\text { homeopathic remedy? }\end{array}$ & & & & \\
\hline Yes & $78(93)$ & $86(36)$ & $74(57)$ & 0.336 \\
\hline No & $3(4)$ & $2(1)$ & $4(3)$ & \\
\hline Do not know & $18(22)$ & $12(5)$ & $22(17)$ & \\
\hline
\end{tabular}

${ }^{2}$ Due to different response rates to each question, the numbers do not always add up to the same number. 
Table 4: : Categorization of the participant's initial complaints, diseases or diagnosis according to ICPC-2. Worsening of symptoms coded according to CTCAE 1-5 grading system and differentiation of [AE(all)] into HA or AE according to Stub et al.

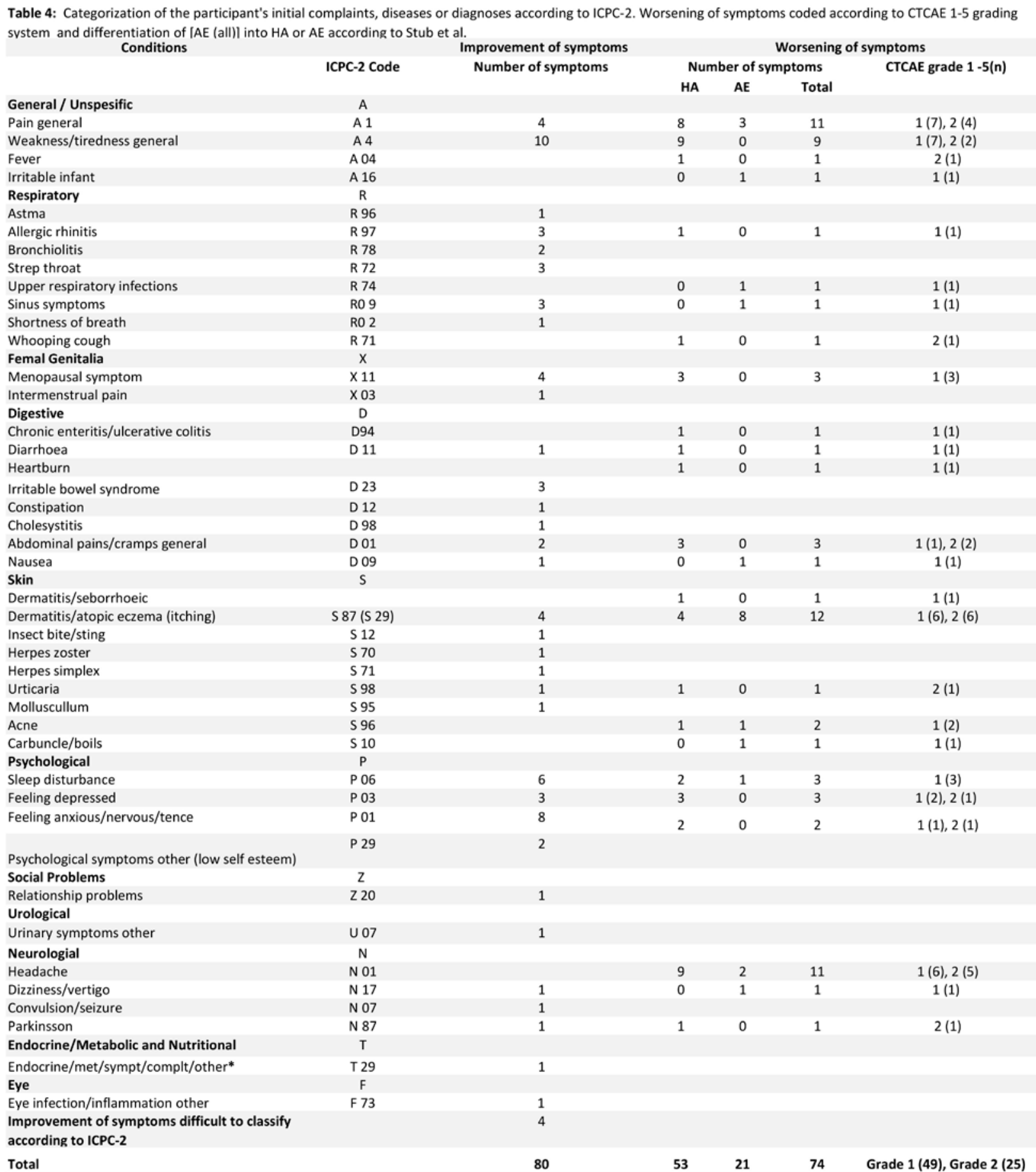

AE: Adverse events, HA: Homeopathic aggravations, $n=$ number of participants, * Endocrine/metabolic/complaint/other.

As some participants reported more than one symptom, the number of symptoms may differ from the number of participants. 
